\title{
ORMELOXIFENE: A NEW DRUG TREATMENT MODALITY IN DUB AND ITS COMPARISON WITH NORETHISTERONE
}

\author{
Vandana Kumari ${ }^{1}$, Priti Bala Sahay² \\ 12 $2^{\text {nd }}$ Year Junior Resident, Department of Obstetrics and Gynaecology, Rajendra Institute of Medical Sciences (RIMS), Ranchi. \\ 2Professor and HOD, Department of Obstetrics and Gynaecology, Rajendra Institute of Medical Sciences (RIMS), Ranchi.
}

\begin{tabular}{l} 
ABSTRACT \\
\hline BACKGROUND \\
AUB refers to bleeding that is excessive or occurs outside of normal cyclic menstruation. DUB is abnormal uterine bleeding in \\
absence of any systemic, organic or iatrogenic cause. It is a diagnosis of exclusion. The objective of this study was to highlight the \\
role of ormeloxifene as a treatment modality in DUB and compare it with norethisterone.
\end{tabular}

\section{MATERIALS AND METHODS}

This was a prospective study carried out in Department of Obstetrics and Gynaecology, RIMS, Ranchi, over a period of 6 months. 60 women presenting with DUB were selected. Group A consisted of 30 women who were given ormeloxifene and Group B consisted of rest 30 women who were given norethisterone. Both groups were followed at 1, 3 and 6 months.

\section{RESULTS}

The evaluation criteria set were menstrual blood loss assessment by PBAC score, rise in HB and endometrial thickness as measured by TVS. There was marked improvement in HB from 7.64 to 10 in Group A as compared to 8.8 in Group B at end of 6 months. PBAC score also sharply reduced from 210 to 80 in Group B after this timespan. Endometrial thickness reduced from 12.1 $\mathrm{mm}$ to $8.4 \mathrm{~mm}$ and $12.08 \mathrm{~mm}$ to $9.8 \mathrm{~mm}$ in Group A and B respectively. No major side effects were noted in either of the groups.

\section{CONCLUSION}

This study helps in concluding that Ormeloxifene is a viable drug option in medical management of DUB. It provides contraception in reproductive age group at the same time.

\section{KEYWORDS}

Dysfunctional Uterine Bleeding, Hysterectomy, Norethisterone, Ormeloxifene, Pictoral Blood Loss Assessment Score (PBAC), Transvaginal Sonography (TVS).

HOW TO CITE THIS ARTICLE: Kumari V, Sahay PB. Ormeloxifene: a new drug treatment modality in DUB and its comparison with norethisterone. J. Evolution Med. Dent. Sci. 2016;5(83):6199-6201, DOI: 10.14260/Jemds/2016/1400

\section{BACKGROUND}

AUB refers to bleeding that is excessive or occurs outside of normal cyclic menstruation. DUB is abnormal uterine bleeding in absence of any systemic, organic or iatrogenic cause. ${ }^{1}$ It is a diagnosis of exclusion. The exact mechanism of DUB is uncertain, but is believed to be caused by dysfunctions of hypothalamic-pituitary ovarian axis. DUB is the most common cause of Abnormal Uterine bleeding and is a major indication for referral to GOPD. ${ }^{2}$ It has several adverse effects including anaemia, reduced quality of life and increased health care costs. Hysterectomy is a definite cure for DUB, but it has its own morbidity and long-term complications like premature ovarian failure, cardiovascular disease and intestinal or urinary dysfunctions. Thus, drug therapy should be first line treatment before recourse to surgery. ${ }^{3}$

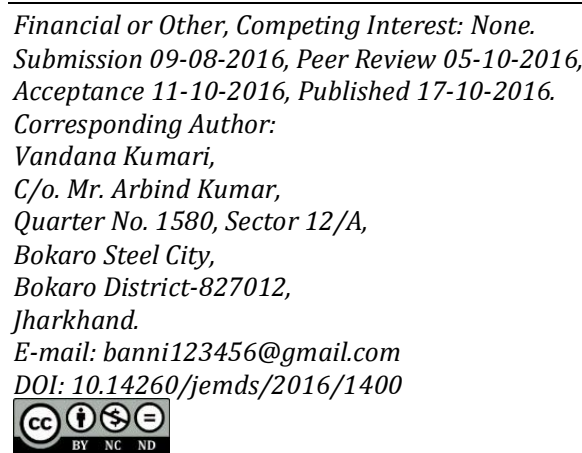

\section{AIM OF THE STUDY}

The aim of this study was to highlight the role of Ormeloxifene as a new drug treatment modality in DUB and compare it with one of the most commonly used drug norethisterone.

\section{Ormeloxifene}

Ormeloxifene is one of the $3^{\text {rd }}$ generation Selective Oestrogen Receptor Modulator (SERM). It is best known as a nonhormonal non-steroidal oral contraceptive taken once a week. It is one of those few drugs which are pride of our nation, as it is developed by Central Drug Research Institute (CDRI), Lucknow, India. Ormeloxifene is marketed under trade name Novex-DS, Centron, Sevista, etc. It is primarily used as a contraceptive. Other uses are for treatment of menorrhagia, mastalgia, fibroadenoma and as chemotherapeutic agent in advanced breast cancer. It is contraindicated in polycystic ovarian disease, active liver disease, cervical growth, recent history of jaundice. It is a category $\mathrm{C}$ drug in pregnancy. Its contraceptive dose is $30 \mathrm{mg}$ twice a week for 1 st 12 weeks, then $30 \mathrm{mg} /$ week from 13 $13^{\text {th }}$ week onwards. Adult dose is $60 \mathrm{mg}$ twice a week for first 12 weeks, then $60 \mathrm{mg}$ once a week for up to next 12 weeks.

\section{MATERIALS AND METHODS}

This was a prospective study carried out in Department of Obstetrics and Gynaecology, RIMS, Ranchi, over a span of 6 months from February 2013 to July 2013; 60 women presenting with abnormal uterine bleeding without any 
organic, systemic or iatrogenic cause were selected. Detailed history and examination done. Investigations included complete blood count, urine pregnancy test, TSH, coagulation profile, Pap smear, pelvic ultrasound (to measure endometrial thickness and rule out any pelvic pathology). Inclusion criteria chosen was women between menarche upto 51 years of age with menorrhagia. Exclusion criteria included pregnancy, bleeding disorders, medical disorders, liver dysfunction, heart disease, migraine, stroke, renal disease, hypo/hyperthyroidism. Evaluation criteria set were menstrual blood loss assessment by PBAC score, $\mathrm{Hb} \%$, endometrial thickness in proliferative phase by TVS. Work-up chart included Group A consisting of 30 women who were given Tab. ormeloxifene $60 \mathrm{mg}$ twice a week for first 12 weeks followed by once a week for next 12 weeks. Group B consisting of remaining 30 women were given norethisterone $5 \mathrm{mg} \mathrm{BD}$ for 21 days for 6 cycles. Both groups were followed at 1, 3 and 6 months. At each visit detailed menstrual history taken, PBAC score calculated, $\mathrm{Hb} \%$ calculated and endometrial thickness measured by TVS. No side effects were noted in each group, except occasional episodes of nausea and vomiting.

\section{Ethics}

Procedures followed were in accordance with the Ethical Standards of RIMS Ethical Committee on human experimentation and with the Helsinki Declaration of 1975 that was revised in 2000. Informed consent was taken.

\section{RESULTS}

The reduction in mean PBAC score with ormeloxifene (220 to 82 ) was significantly more than norethisterone (254 to 160) at 6 months $(\mathrm{p}<0.01)$. The rise in haemoglobin concentration and fall in endometrial thickness $(7.42 \mathrm{~g} \%$ to $9.2 \mathrm{~g} \%$ as compared to $7.48 \mathrm{~g} \%$ to $8.6 \mathrm{~g} \%, \mathrm{p}<0.05$ and $12.20 \mathrm{~mm}$ to 9.46 $\mathrm{mm}$ vs $12.10 \mathrm{~mm}$ to $10.6 \mathrm{~mm}, \mathrm{p}<0.05$, respectively) were also significantly more with ormeloxifene than norethisterone.

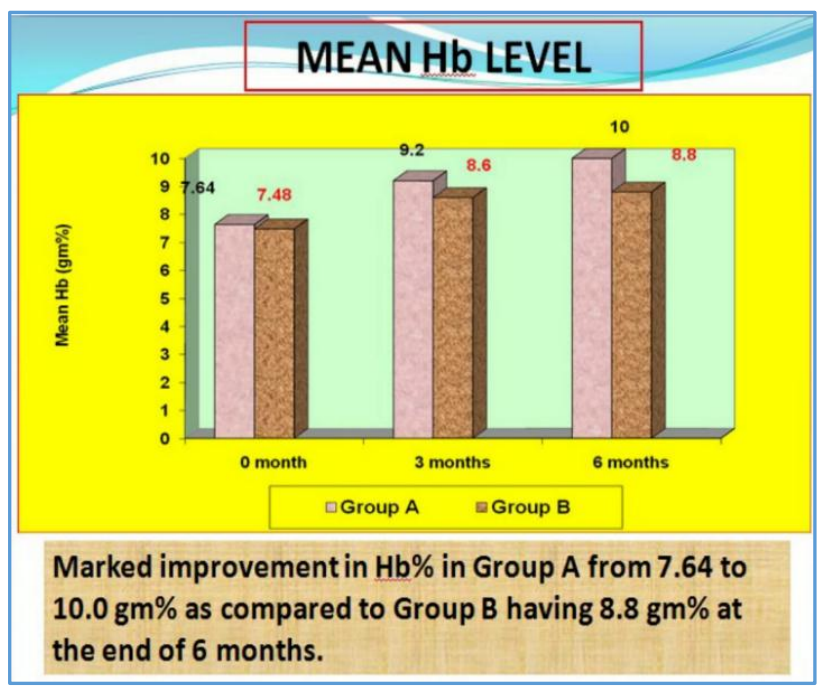

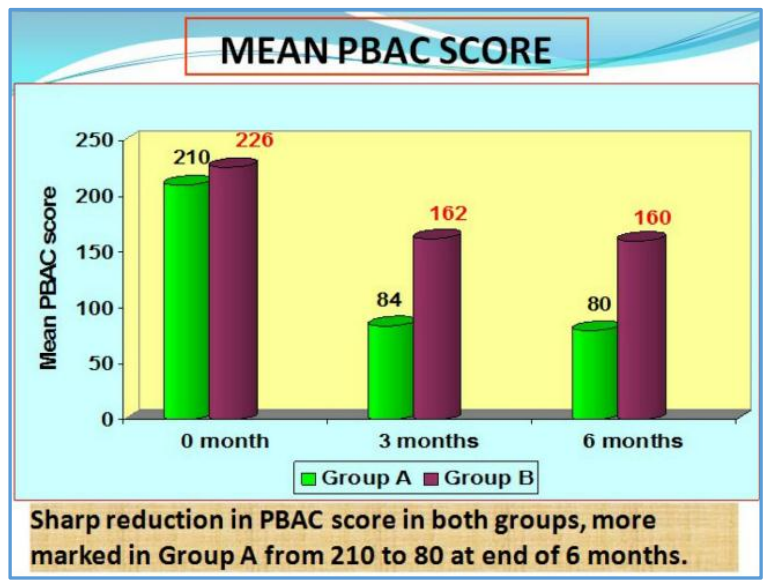
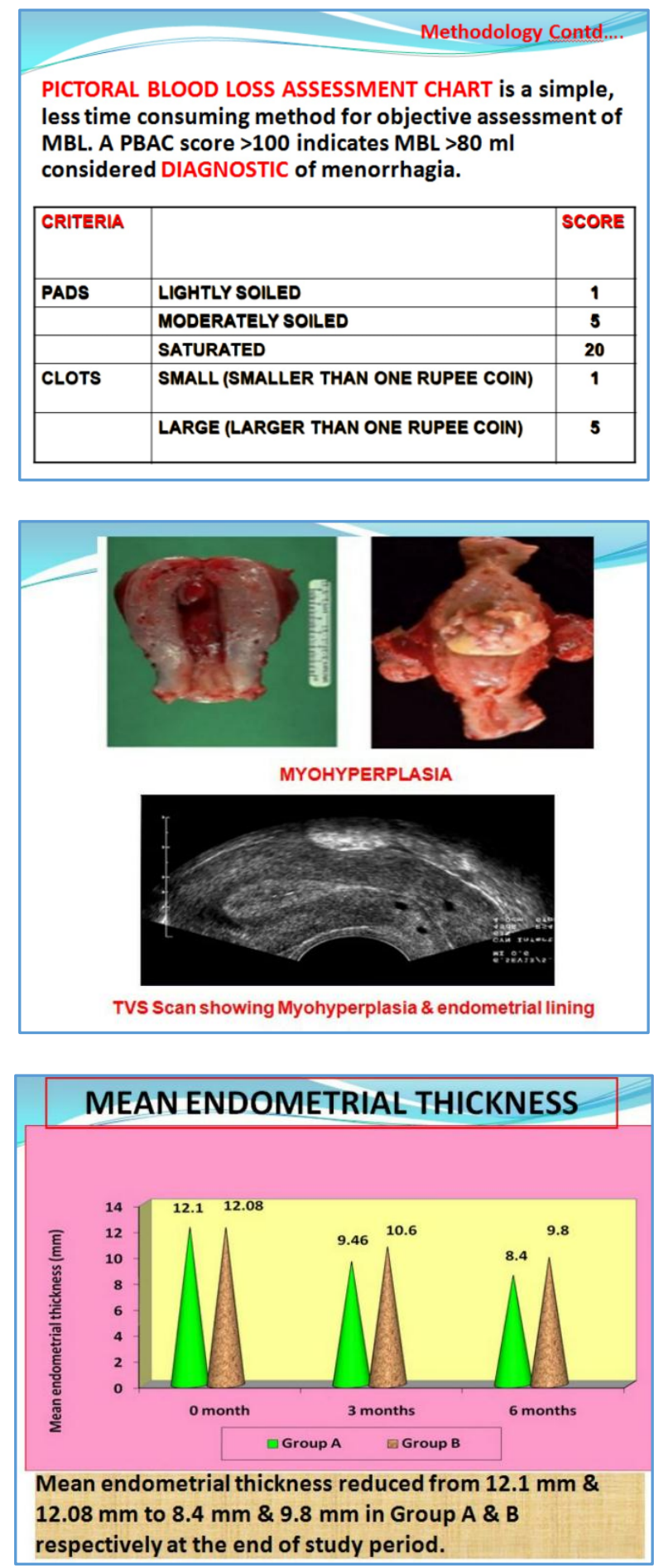


\begin{tabular}{|l|c|c|c|c|}
\hline \multicolumn{5}{|c|}{$\begin{array}{r}\text { SUBJECTIVE ASSESSMENT OF } \\
\text { IMPROVEMENT }\end{array}$} \\
\hline \begin{tabular}{l|c|c|c|} 
SUBJECTIVE \\
IMPROVEMENT
\end{tabular} & \multicolumn{2}{|c|}{ GROUP A } & \multicolumn{2}{c|}{ GROUP B } \\
\cline { 2 - 5 } No improvement & 2 & 6.66 & 4 & 13.3 \\
\hline Mild Improvement & 6 & 20 & 6 & 20 \\
\hline Moderate improvement & 22 & 73.3 & 20 & 66.6 \\
\hline Worsening of symptoms & 0 & 0 & 0 & 0 \\
\hline Total & 30 & 100 & 30 & 100 \\
\hline
\end{tabular}

\section{DISCUSSION AND CONCLUSION}

Medical management of DUB should aim to relieve symptoms, improve quality of life and avoid risk of surgery. For women who have not completed their family or are unfit for surgery or wish to retain their menstrual or reproductive functions, medical management is only viable option. So many drugs are available, but there is a general lack of evidence based approach, marked variation in practice and continuing uncertainty regarding most appropriate therapy. There are few studies regarding role of ormeloxifene in DUB and its comparison with progesterone.
Both norethisterone and ormeloxifene are effective in treating DUB, but ormeloxifene is superior to norethisterone as assessed by reduction in menstrual blood loss (Fall in PBAC score and patient subjective assessment), rise in $\mathrm{Hb}$ concentration and decrease in endometrial thickness. It is especially beneficial to patient who prefers non-steroidal treatment, wish to preserve fertility and in whom steroidal treatment is not recommended. Ormeloxifene appears to be a good option in adolescents and women of perimenopausal age group (improvement in lipid profile). For women who desire contraception, this is definitely a better choice. There is ease of administration because of long half-life resulting in improved compliance and acceptability.

But the study needs further validation (by double blind placebo-controlled randomised trials) before routine recommendation.

\section{REFERENCES}

1. Dadhich S, Agarwal S, Soni M, et al. Role of ormeloxifene in medical management of dysfunctional uterine bleeding. Asian J Obstet Gynaecol Practice 2012;6:28-31.

2. Frick KD, Clark MA, Steinwachs DM, et al. STOP-DUB Research group. Financial and quality of life burden of DUB among women agreeing to obtain surgical treatment. Women Health Issues 2009;19(1):70-8.

3. Macdonald R. Modern treatment of menorrhagia. Br J Obstet Gynaecol 1990;97(1):3-7. 